\title{
Rates and Correlates of Self-Reported Pap Testing in African-Caribbean-Black HIV-Positive Women in Ontario, Canada
}

\author{
Nisha Andany ${ }^{1}$, Juan Liu ${ }^{2}$, Robert Remis ${ }^{2,3}$, Rupert Kaul ${ }^{1,4}$, Wangari Esther Tharao ${ }^{5}$ and Mona Loutfy $1,2,6,7^{\star}$ \\ ${ }^{1}$ Department of Medicine, University of Toronto, Toronto, Ontario, Canada \\ ${ }^{2}$ Dalla Lana School of Public Health, Toronto, Ontario, Canada \\ ${ }^{3}$ Public Health Ontario, Etobicoke, Ontario, Canada \\ ${ }^{4}$ University Health Network, Toronto, Ontario, Canada \\ ${ }^{5}$ Women's Health in Women's Hands, Toronto, Ontario, Canada \\ ${ }^{6}$ Maple Leaf Medical Clinic, Toronto, Ontario, Canada \\ ${ }^{7}$ Women's College Research Institute, Women's College Hospital, Toronto, Ontario, Canada
}

"Corresponding author: Mona Loutfy, Women's College Research Institute, Women's College Hospital, 790 Bay Street, Room 736, Toronto, Ontario M5G 2N8 Canada; Tel: 416-351-3732; Fax: 416-351-3746; E-mail: mona.loutfy@wchospital.ca

Received date: August 13, 2014; Accepted date: October 24, 2014; Published date: October 27, 2014

Copyright: $\odot 2014$ Andany N, et al. This is an open-access article distributed under the terms of the Creative Commons Attribution License, which permits unrestricted use, distribution, and reproduction in any medium, provided the original author and source are credited.

\begin{abstract}
Cervical dysplasia and cancer are more common and aggressive in HIV-positive women and Papanicolaou (Pap) testing allows for their earlier identification and treatment. Guidelines recommend annual screening for this population. This cross-sectional study assessed prevalence and correlates of self-reported Pap testing among African-Caribbean-Black HIV-positive women who completed an ACASI-administered questionnaire. Participants were recruited through a community health centre in Toronto, Canada. Pap testing history was assessed by a single question asking when the last test was done. Logistic regression examined correlates of Pap testing in the previous year. The 126 participating women's median age was 40 years (IQR=34-46); $53.2 \%$ were East African and $16.7 \%$ Caribbean. $69.9 \%$ and $82.1 \%$ of women had received a Pap test in the previous year and three years, respectively; $10.6 \%$ had never been tested. Age: $35-49$ vs. $>50$ years $(O R=6.7,95 \%, C l=1.7-25.1)$, being in Canada for $>2$ years $(\mathrm{OR}=4.6,95 \%, \mathrm{Cl}=1.6-13.5)$, having $>2$ sexual partners $(\mathrm{OR}=3.4,95 \%, \mathrm{Cl}=1.1-10.7)$ or having seen a family doctor within 6 months $(\mathrm{OR}=2.6,95 \%, \mathrm{Cl}=1.1-6.2)$ were significantly associated with Pap testing in the past year. In conclusion, $70 \%$ of participating women did have Pap screening in the past year. Program development to reach the $30 \%$ under-screened women should be sought; especially for the $10 \%$ who never received screening.
\end{abstract}

Keywords: HIV; Cervical cancer; Pap testing; Human Papilloma Virus (HPV)

\section{Introduction}

Cervical dysplasia and cancer caused by the Human Papilloma Virus (HPV) is a significant health burden; globally, cervical cancer is the $4^{\text {th }}$ most common cancer among women, with incidence and mortality being highest in developing countries [1]. In 2012, there were approximately 528,000 new cases of cervical cancer worldwide and 266,000 deaths, with $87 \%$ of deaths occurring in the developing world [1]. In Canada in 2012, the incidence of cervical cancer was 1,350 new cases, with 390 deaths [2]. Papanicolaou (Pap) cytology testing identifies pre-invasive cervical lesions and allows for the early treatment of high-grade dysplasia and the prevention of invasive cervical cancer. In a study of 13,424 patients in Canada, survival rates from cervical cancer have improved between 1992-2005 in all age groups and among all histologic subtypes and geographical regions [3]. Within Ontario, between 1981 and 2009, incidence of cervical cancer decreased by $38 \%$ and mortality decreased by $59 \%$ [4]. The current screening guidelines in Ontario suggest that sexually active women undergo Pap cytology testing beginning at age 21 years [4,5]. Screening should occur every three years and can be discontinued at the age of 70 years, as long as there is an adequate normal cytology history within the previous 10 years (i.e. three or more normal Pap tests) $[4,5]$.

Screening for cervical cancer is especially important in women with HIV, as cervical dysplasia and cancer are more common and aggressive amongst them [6-11]. Women with HIV are four times more likely to develop cervical cancer than the general population due to impairment of specific immune responses required to control HPV infection [11]. HIV-1 is classified as being carcinogenic to humans by the International Agency for Research on Cancer [12]; its carcinogenicity operates predominantly via immunosuppression, allowing for increased activity of other oncogenic infections and impaired cellular surveillance [10,13]. Despite the availability of effective combination Antiretroviral Therapy (ART), the incidence of HPV-associated cancers, including cervical and anal cancer, has not decreased in the HIV-positive population [10,14-16].

The current guidelines for frequency of cervical cancer screening among the HIV-positive population are different than the general population: women with HIV should be screened twice in the first year after diagnosis; if two consecutive Pap tests, done 6 months apart, are normal, the screening interval can be extended to one year [17]. For many women with HIV, socio-economic challenges and cultural factors may present barriers to optimal cervical cancer screening [18-23]. On the other hand, women with HIV also have frequent contact with health care providers, a factor which has been shown to 
increase adherence to regular Pap screening [24-25]. There have been several studies examining Pap testing in the HIV-positive community and rates of screening range from $30 \%$ to $88 \%$ [26-34]. Factors associated with regular screening include access to a primary care physician [30] or gynecologist [27-29], while the lack of regular screening is predicted by older [28,35,36] or younger [29] age, lower education level $[29,35]$, intravenous drug use $[26,35,36]$ and having a CD4+ count $<200$ cells/mm $[3,29,36]$.

In Canada, women make up 23\% of the HIV-positive population [37]. From 2009-2011, 23.9\% of new HIV diagnoses in Ontario were in Black persons [38]. Fifty-four percent of positive HIV test reports in women occur in those who are from a country of high HIV prevalence (i.e. HIV-endemic country) [39], most likely to be a country in Africa or the Caribbean. Since 1998, the racial/ethnic composition in the proportion of positive tests in women has been changing. The proportion of new HIV diagnoses in women that occurred in White patients decreased from $53.3 \%$ in 1998 to $18.7 \%$ in 2008 ; conversely, the proportion of new female cases occurring in Black women between 1999-2008 increased from $12.2 \%$ to $26.3 \%$ [39]. There have not been any studies specifically examining rates of Pap testing among African Caribbean Black (ACB) women who are HIV-positive. This is of interest, as differences in cervical cancer screening rates in the general population have been observed for several socioeconomic variables relevant to ACB women. Studies have revealed that women living in poorer neighborhoods and who are urban immigrants, groups which are more likely to include ACB women, have lower rates of Pap testing [20]. The objective of the present study was to determine rates and correlates of self-reported Pap testing among ACB women with HIV attending a community health centre in downtown Toronto.

\section{Methods}

\section{Study population}

Women were recruited to participate in the study from Women's Health in Women's Hands (WHIWH) between April 2009 and October 2010. WHIWH is a community health centre located in downtown Toronto, Canada that provides a broad range of health care services, including primary health care, for approximately 9,000 Black women and other women of color, particularly immigrant and refugee women. Criteria for inclusion in the study were: 1) 16 years of age or older and 2) either the participant, or one of their parents or grandparents, was born in Africa or the Caribbean. Both HIV-positive and HIV-negative women were recruited to participate; for the present study, the statistical analysis has been limited to HIV-positive women. Participants were only included if written informed consent was provided. The study was approved by the University of Toronto Research Ethics Board.

\section{Study Design}

The current analysis was a sub-investigation of a larger study, which was carried out using a cross-sectional design consisting of a single visit (described in detail elsewhere) [40]. During the study visit, the participants completed a detailed self-administered survey of 110 questions using the Audio and Computer Assisted Self-administered Interviewing (ACASI) system. The survey assessed demographic characteristics (age, education, country of birth and immigration information, religion, marital status, etc), pregnancy history, sexual and gynecologic history (contraception use, number of previous partners, Sexually Transmitted Infection (STI) history, Pap testing history), general medical history and health-related behaviours (smoking, alcohol, drug use), and access to health services. The questionnaire was adapted from the Canadian Community Health Survey (CCHS), which was developed to assess health status, health care utilization and health determinants for the Canadian population [41]. The CCHS is administered by Statistics Canada and was developed through collaborative efforts between Statistics Canada and specialists from other provincial/federal departments and academic fields.

\section{Description of the Pap Testing Questioning}

Information on Pap testing was assessed by two questions in the survey. The first question asked, "when was your last Pap test?" Participants were asked to choose one response from the options of a) never, b) less than 6 months ago, c) 6 months to less than one year ago, d) one year to less than three years ago, e) three years to less than five years ago, f) more than five years ago, g) don't know, or h) refuse to answer. For those who responded that their last Pap had been more than three years ago, a follow up question asked, "why have you never had a Pap test in the past three years?" Response options included a) have not gotten around to it, b) did not think it was necessary, c) doctor did not think it was necessary, d) personal or family responsibilities, e) not available at the time it was required, f) not available in the area, g) wait time was too long, h) transportation issues, i) language problems, $\mathrm{j}$ ) cost issues, $\mathrm{k}$ ) not knowing where to go, l) worried about pain or embarrassment, $m$ ) fear of finding something wrong or $\mathrm{n}$ ) other reasons.

\section{Statistical Analysis}

Baseline characteristics were summarized using frequencies and proportions for categorical variables and medians with Interquartile Ranges (IQR) for continuous variables. Our primary analysis was to determine the proportion of women who reported having a Pap test in the past year. Secondary analyses included assessing the proportion of women who have had a Pap test in the past three years, reasons for not receiving a Pap test in the past three years and to determine the demographic, socio-economic, cultural and behavioural factors associated with a lack of Pap testing in the past year. The rates of Pap testing among HIV-positive women were summarized with frequencies and proportions. Correlates of Pap testing in the past one year were determined using logistic regression models; those correlates that were significant in the univariate model $(\mathrm{p}<0.10)$ were considered for incorporation into multivariable models.

\section{Results}

\section{Baseline characteristics}

A total of 126 HIV-positive women completed the questionnaire. Median age was 40 years (IQR 34-46). The majority of women reported heterosexual contact as the route of HIV acquisition. Fifty-three percent of respondents were born in East Africa, while 14.3\% were from Southern Africa, $8.7 \%$ from West Africa and 16.7\% from the Caribbean. Participants had been in Canada for a median of four years (IQR 2-11). Ninety-six percent were on ART at the time of completing the questionnaire (Table 1). 
Citation: Andany N, Liu J, Remis R, Kaul R, Tharao WE, et al. (2014) Rates and Correlates of Self-Reported Pap Testing in African-Caribbean-

Page 3 of 7

\section{History of Pap testing}

Of the 126 HIV-positive women who participated in the study, $69.9 \%$ reported having a Pap test in the last year. $82 \%$ of respondents had undergone Pap testing in the past three years, while $10.6 \%$ had never had a Pap test. Among women who had not had a Pap test in the past three years, the most common reasons were "not having gotten around to it" (45\%), "not thinking it was necessary" (15\%), "not knowing where to go" (10\%), and "being worried about pain or embarrassment" (10\%). $27 \%$ of women reported that they had had a previously abnormal Pap test and $2.5 \%$ reported a previous diagnosis of cervical cancer (Table 2).

\begin{tabular}{|c|c|}
\hline Variable & Median (IQR) or Number (Proportion) \\
\hline Age & Median 40 years $(34-46)$ \\
\hline $15-34$ years & $32(25.4 \%)$ \\
\hline $35-49$ years & $78(61.9 \%)$ \\
\hline$\geq$ 50years & $16(12.7 \%)$ \\
\hline \multicolumn{2}{|c|}{ Method of HIV Acquisition ( $n=114)$} \\
\hline Sex with a man & $84(73.7 \%)$ \\
\hline Injection drug use & $2(1.8 \%)$ \\
\hline Blood transfusion & $4(3.5 \%)$ \\
\hline Needle stick injury & $3(2.6 \%)$ \\
\hline Don't know & $12(10.5 \%)$ \\
\hline None of the above & $6(5.3 \%)$ \\
\hline Other & $3(2.6 \%)$ \\
\hline \multicolumn{2}{|l|}{ Region of Birth } \\
\hline Canada & $2(1.6 \%)$ \\
\hline Caribbean & $21(16.7 \%)$ \\
\hline Central Africa & $3(2.4 \%)$ \\
\hline Eastern Africa & $67(53.2 \%)$ \\
\hline Northern Africa & $2(1.6 \%)$ \\
\hline Southern Africa & $18(14.3 \%)$ \\
\hline Western Africa & $11(8.7 \%)$ \\
\hline Other Africa & $1(0.8 \%)$ \\
\hline Other & $1(0.8 \%)$ \\
\hline \multicolumn{2}{|l|}{ Religion } \\
\hline Christian & $104(82.5 \%)$ \\
\hline Muslim & $9(7.1 \%)$ \\
\hline Other & $13(10.3 \%)$ \\
\hline Duration in Canada & Median 4 years $(2-11)$ \\
\hline$<2$ years & $24(19.2 \%)$ \\
\hline $2-4$ years & $39(31.2 \%)$ \\
\hline
\end{tabular}

\begin{tabular}{|c|c|}
\hline $5-9$ years & $27(21.6 \%)$ \\
\hline $10-19$ years & $20(16.0 \%)$ \\
\hline$>20$ years & $15(12.0 \%)$ \\
\hline \multicolumn{2}{|l|}{ HIV Treatment $(n=114)$} \\
\hline Never & $18(15.9 \%)$ \\
\hline $\begin{array}{l}\text { Yes, but not in the past six } \\
\text { months }\end{array}$ & $16(14.2 \%)$ \\
\hline Yes, in the past six months & $79(69.9 \%)$ \\
\hline \multicolumn{2}{|l|}{ Education } \\
\hline No education & $4(3.2 \%)$ \\
\hline $\begin{array}{l}\text { Some/completed Elementary } \\
\text { School }\end{array}$ & $11(8.8 \%)$ \\
\hline $\begin{array}{l}\text { Some/Completed Secondary } \\
\text { School }\end{array}$ & $46(36.8 \%)$ \\
\hline $\begin{array}{l}\text { Some/Completed } \quad \text { College/ } \\
\text { University }\end{array}$ & $61(48.8 \%)$ \\
\hline $\begin{array}{l}\text { Some/Completed Graduate } \\
\text { Education }\end{array}$ & $3(2.4 \%)$ \\
\hline \multicolumn{2}{|l|}{ Household Income } \\
\hline Less than $\$ 10,000$ & $38(35.2 \%)$ \\
\hline$\$ 10,000-\$ 19,999$ & $37(34.3 \%)$ \\
\hline$\$ 20,000-\$ 49,999$ & $30(27.8 \%)$ \\
\hline$\$ 50,000$ or more & $3(2.8 \%)$ \\
\hline Having a Family MD & $112(89.6 \%)$ \\
\hline $\begin{array}{l}\text { Having seen family MD in last } \\
\text { six months }\end{array}$ & $67(53.6 \%)$ \\
\hline $\begin{array}{l}\text { Having seen HIV specialist in } \\
\text { last six months }\end{array}$ & $67(53.6 \%)$ \\
\hline
\end{tabular}

Table 1: Baseline characteristics of 126 HIV-Positive ACB Women in Study Population. ACB: African Caribbean Black; IQR: Interquartile Range; MD: Medical Doctor.

\begin{tabular}{|c|c|}
\hline & Number (Proportion) \\
\hline \multicolumn{2}{|l|}{ Timing of Last Pap Test } \\
\hline Never & $13(10.6 \%)$ \\
\hline Pap Test In Past One Year & $86(69.9 \%)$ \\
\hline Pap Test in Past Three Years & $101(82.1 \%)$ \\
\hline Tested $>3$ years ago & $9(7.1 \%)$ \\
\hline \multicolumn{2}{|l|}{ Pap Results } \\
\hline Previous abnormal Pap & $29(26.9 \%)$ \\
\hline Previous diagnosis of cervical cancer & $3(2.5 \%)$ \\
\hline
\end{tabular}




\begin{tabular}{|l|c|}
\hline Not gotten around to it & $9(45.0 \%)$ \\
\hline Did not think it was necessary & $3(15.0 \%)$ \\
\hline Did not know where to go & $2(10.0 \%)$ \\
\hline Worried about pain or embarrassment & $2(10.0 \%)$ \\
\hline Fear of finding something wrong & $1(5.0 \%)$ \\
\hline Other & $4(20.0 \%)$ \\
\hline
\end{tabular}

Table 2: Frequency and results of Pap-testing and reasons for no testing.

\section{Correlates of Pap Testing}

Correlates of self-reported Pap testing in the past one year can be found in Table 3. Correlates significant in univariate analyses included age, duration in Canada, number of sexual partners and access to a primary care practitioner. Women were more likely to have been screened in the past year if they were aged 35-49 years, compared to those over the age of $50(\mathrm{OR}=6.7,95 \% \mathrm{CI} 1.7-25.1, \mathrm{p}=0.0013)$, and there was a trend for them to have higher rates of screening than those aged 15-34 years (OR 2.8, 95\% CI 0.69-11.6, $\mathrm{p}=0.10$ ). Having a Pap test in the past one year was also associated with having been in Canada for $>2$ years $(\mathrm{OR}=4.6,95 \%$ CI 1.6-13.5, $\mathrm{p}=0.0012)$, having had $>2$ sexual partners $(\mathrm{OR}=3.4,95 \% \mathrm{CI} 1.1-10.7, \mathrm{p}=0.018)$, being infected via heterosexual transmission $(\mathrm{OR}=3.2,95 \% \mathrm{CI} 1.0-10.4, \mathrm{p}=0.025)$ and having seen a family doctor within the past six months (OR=2.6, 95\% CI 1.1-6.2, $\mathrm{p}=0.017)$. There was a trend towards higher rates of testing in women reporting an annual household income greater than $\$ 10,000$ $(\mathrm{OR}=2.4,95 \% \mathrm{CI} 0.92-6.3, \mathrm{p}=0.045)$ and in those having completed at least some secondary school education compared to those who had not attended school or only had elementary-level education (OR=3.1, 95\% CI 0.91-10.5, $\mathrm{p}=0.068$ ). Region of birth, religion, marital status, number of previous pregnancies, age at first sexual intercourse, history of STIs, ART and having seen an HIV specialist were not associated with rates of Pap testing in the past one year. No variables were significant in multivariate analyses (Table 3).

\section{Discussion}

Cervical cancer continues to be a significant health burden among women $[1,2]$. Since the introduction of Pap cytology testing, the incidence and mortality of invasive cervical cancer have improved significantly $[3,4,42]$, such that the diagnosis of invasive cervical cancer now represents a failure to prevent HPV progression and occurs predominantly in women who have been inadequately screened [43-45]. Women with HIV are particularly susceptible to the development of cervical dysplasia and the recommended screening frequency is different than that of the general population [17]. In our study of ACB HIV-positive women attending a Toronto community health centre, approximately $70 \%$ reported having a Pap test in the past year and $82 \%$ had had a test within the last three years (which is the recommended screening interval for HIV-negative women in Ontario). Unfortunately, $7 \%$ of women had not undergone Pap testing in over 3 years and $10.6 \%$ had never had a Pap test.

To our knowledge, there has been only one other study examining rates of Pap testing in HIV-positive women in Ontario. Leece and colleagues conducted a retrospective chart review of $218 \mathrm{HIV}$-positive women in Ottawa between 2002-2005 and found that only 58\% had undergone Pap testing within a three-year period [30]. While this study did not specifically distinguish by race/ethnicity, there was no difference between rates of Pap testing between HIV-positive women from endemic countries and those who were not from endemic countries [30]. It is possible that the discrepancy in overall Pap rates between their study and our study is due to the different time periods and the different locations between the two studies. Rates of Pap testing in the general female population across Ontario have been increasing over time: in 2001, only $41 \%$ of women had had a Pap test within the past year (the recommended screening interval at that time was every one to two years) [46]. In 2004-2005, 69\% of women in Ontario had undergone Pap testing within the preceding three years [47]; by 2008-2010, rates had improved to $72 \%$ [48]. In fact, the screening rate of $58 \%$ in the Leece study (2002-2005) is comparable to the rate of screening in the urban female population in Ontario between 2003-2005, which was 61\% [20]. Similarly, the rate of appropriate screening in our study population $(70 \%)$ corresponds to that of the general population in Ontario; in a population-based study of 3.7 million Ontario women aged 20-69 years between 2008-2010, $72 \%$ had undergone Pap testing within the aforementioned three-year interval [48].

\begin{tabular}{|l|c|}
\hline Variable & Odds Ratio (95\% confidence interval) \\
\hline Age (vs. $>\mathbf{5 0}$ years) & $2.6(0.69-11.6)$ \\
\hline $15-34$ years & $6.7(1.8-25.1)$ \\
\hline $35-49$ years & $4.6(1.6-13.5)$ \\
\hline Duration in Canada (>2 years) & $3.1(0.91-10.5)$ \\
\hline Education (vs. elementary/none) Secondary/above & $2.4(0.92-6.3)$ \\
\hline Annual Household Income (vs. $<\mathbf{\$ 1 0}, \mathbf{0 0 0})$ & $3.4(1.1-10.7)$ \\
\hline$>\$ 10,000$ & \\
\hline Male Sexual Partners $(>\mathbf{2}$ lifetime) & \\
\hline
\end{tabular}




\begin{tabular}{|l|c|}
\hline Saw family MD in last 6 months & $2.6(1.1-6.2)$ \\
\hline How Infected with HIV & $3.2(1.0-10.4)$ \\
\hline Sex with a man & \multicolumn{2}{|c|}{} \\
\hline
\end{tabular}

Table 3: Predictors of Pap-testing in past one year (Univariate Analysis). MD: Medical Doctor.

The rate of self-reported Pap testing in this study is higher than those reported by HIV-positive women in some European countries, but is lower than rates of screening in HIV-positive women in the United States [27-29]. In a study of 1,002 Italian HIV-positive women assessed between 2006-2007, 61\% self-reported having a Pap test in the past year [29]. On the other hand, a study of 2,417 women in the United States between 2000-2004 demonstrated a self-reported Pap testing rate of $77 \%$ within one year [28], and a population-based American study between 1996-1997 reported an annual testing rate of $81 \%$ in their HIV-positive women [27]. These discrepancies might be related to regional differences in healthcare delivery models and in population composition and characteristics. Pap testing rates in the general population tend to be lower in Canada compared to the United States [49]. Furthermore, our study was comprised of $100 \%$ ACB women ( $80 \%$ African), with $<2 \%$ having been born in Canada; in the Italian study, only $20 \%$ of women were born outside of Italy [29].

We were able to identify several factors that correlate with rates of Pap testing. Women were more likely to have had a Pap test in the past year if they were aged 35-50 years, compared to women over the age of 50 years. Older age has consistently been associated with poor adherence to Pap testing in both HIV-positive and HIV-negative women $[20,21,28,35,36,49-51]$. The association between older age and lack of Pap testing may be related to the misconception that Pap testing is no longer necessary after menopause [20,52]. Sadly, there is a linear relationship between diagnosis of cervical cancer and age $[44,48,53]$, with most deaths from invasive cervical cancer occurring in those over the age of 50 years [54]; therefore continued Pap testing in older women is essential.

There was also a trend toward women aged 35-50 years having a higher rate of screening when compared to younger women between the ages of 15-34 years. There is evidence to support lower rates of Pap testing in younger women; in a study of 13,745 women in the United States, those aged 25-44 years were significantly more likely (88.7\%) to have had recent Pap testing compared to both women over the age of 65 years $(75.6 \%)$ and those aged $18-24$ years (73.7\%) [50]. Lofters and colleagues assessed 455,864 immigrant women in Ontario between 2006-2008 and determined that being in either the youngest (18-34 years) or oldest (50-66 years) age group was associated with poorer adherence to screening guidelines [21]. In an assessment of 408 adolescents with HIV (ages 13-24 years), only 49\% had ever had a Pap test [33]. Lower Pap rates in this population may in part be affected by uncertainty regarding the benefits of screening in younger women and the optimal timing of screening initiation. In the context of HIV, cervical cancer screening is important for girls who are perinatally infected and guidelines indicated that they should begin undergoing Pap testing within one year of onset of sexual activity and should continue annually for life [17].

We also found that women with $>2$ lifetime sexual partners were more likely to have had a recent Pap test. This finding might be partly collinear with age in that number of sexual partners increases with age.
Studies have also shown that women with a history of STIs and/or pregnancy, which may correlate with number of sexual partners, are more likely to undergo Pap screening $[28,33]$. Having acquired HIV heterosexually was also associated with better adherence to Pap testing (OR 3.2); this is in keeping with multiple other studies, which have determined that women who acquire HIV perinatally [33], and women who use intravenous drugs $[8,24,26,36,53]$, have poorer screening rates than those who acquire HIV through sexual intercourse with a male.

Pap testing was also associated with having been in Canada for $>2$ years. The majority of women in our study (98\%) were born outside of Canada, and immigration has been found to present a barrier to optimal cervical cancer screening and follow-up $[18,20,50]$. In our study however, screening rate in the past year $(70 \%)$ was similar to the rate of appropriate screening in the general female population in Ontario (72\%) (every three years). In one study, screening rates were found to be particularly low in women who had registered for national health insurance within the past 10 years, suggesting that it is recent immigration in particular that is a risk factor for inadequate screening [20]. Similarly, Kaplan and colleagues determined that Pap testing is less frequent in HIV-positive women who have been in care for less than one year [26]. Women who have been in Canada for $>2$ years have likely had more opportunity to become engaged in care with a health care provider. In support of this, we also found that Pap testing was associated with having seen a family physician within the past six months, suggesting that, at least for women with HIV who are retained in care, screening patterns may be better than among the general female population.

There was also a trend towards women with at least some secondary school education and an annual household income of $>\$ 10,000$ being more likely to have had a Pap test in the past year. This is not unexpected; in a previous study in Ontario, the three-year screening rate was lower for women residing in neighborhoods with the lowest income quintile $(64.9 \%)$ compared to women residing in the highest income quintile neighbourhoods (78.5\%) [48]. Studies examining screening in HIV-positive women have consistently found that having less than high school education is associated with poorer adherence to Pap testing guidelines $[29,35,55,56]$.

In our study, $15 \%$ of women had not had a Pap test in the past three years because they "did not think it was necessary" and another $45 \%$ had "not gotten around to it", which may also indicate a lack of understanding of the purpose and importance of screening. In a large study of women in the United States, of those who were able to provide a specific reason for not having a Pap test, $10 \%$ stated that a doctor had not told them a Pap was required and an additional $8 \%$ did not think it was necessary [50].

There are several limitations associated with the present study that contribute to important biases that need to be considered. First of all, the population assessed is a specific population of ACB HIV-positive women attending a downtown community health centre in Toronto. 
As the study sample was limited to one particular patient population, as well to a group that was accessing care, the results may not be generalizable to the general population of women with HIV in Ontario or Canada. Also, the Pap screening rates in our study are likely overestimates of the true rate of screening in the general HIV-positive female population in Ontario due to the fact that all assessed women are already engaged in care and have access to health services targeted at an urban immigrant population. Additionally, as rates of Pap testing were assessed by self-report, our study rates will overestimate true screening rates, as study participants may over recall their screening. In addition, other than patient recall, there was no objective method to assess rates and/or characteristics of abnormal screening results. Additionally, the small sample size limits the power of the study, and is likely why multivariable regression analyses were unable to determine any significant correlates of recent Pap screening. Finally, the sampling was non-random which will contribute to selection bias.

To our knowledge, this is only the second study to assess Pap test screening in HIV-infected women in Ontario, and is the first to assess screening among a subgroup of ACB women, who encompass a disproportionate percentage of women affected by HIV in Canada. Clearly, there is a gap in knowledge regarding cervical cancer screening and follow-up among HIV-positive women in Ontario, the province with the largest number of people living with HIV in Canada [39]. An evidence base is needed to inform cervical cancer screening guidelines specific for HIV-positive women. Moreover, it is critical to determine whether there are inequities in access to screening and/or follow-up among women with HIV so that health care interventions can be targeted to the women who need it the most.

\section{Acknowledgements}

The authors would like to thank all participants of the study and the Canadian Institutes of Health Research (Grant \# HET85518) for funding the study. The authors have no conflicts of interest to disclose.

\section{References}

1. Ferlay J, Soerjomataram I, Ervik M, Dikshit R, Eser S, et al. (2013) GLOBOCAN 2012 v1.0, Cancer Incidence and Mortality Worldwide: IARC CancerBase No. 11 [Internet].

Lyon, France: International Agency for Research on Cancer.

2. Canadian Cancer Society's Steering Committee on Cancer Statistics (2012) Canadian Cancer Statistics. Toronto, ON.

3. Akhtar-Danesh N, Elit L, Lytwyn A (2012) Temporal trends in the relative survival among women with cervical cancer in Canada: a population-based study. Int J Gynecol Cancer 22: 1208-1213.

4. Cancer Care Ontario (2012) Prepared by Surveillance, Prevention and Cancer Control, Cancer Care Ontario. Rates were calculated with hysterectomy-corrected population at risk.

5. Cancer Care Ontario (2012) Ontario Cervical Cancer Screening Cytology Guidelines. Toronto, ON.

6. Sun XW, Kuhn L, Ellerbrock TV, Chiasson MA, Bush TJ, et al. (1997) Human papillomavirus infection in women infected with the human immunodeficiency virus. N Engl J Med 337: 1343-1349.

7. Chin KM, Sidhu JS, Janssen RS, Weber JT (1998) Invasive cervical cancer in human immunodeficiency virus-infected and uninfected hospital patients. ObstetGynecol 92: 83-87.

8. Frisch M, Biggar RJ, Goedert JJ (2000) Human papillomavirus-associated cancers in patients with human immunodeficiency virus infection and acquired immunodeficiency syndrome. J Natl Cancer Inst 92: 1500-1510.
9. Grulich AE, van Leeuwen MT, Falster MO, Vajdic CM (2007) Incidence of cancers in people with HIV/AIDS compared with immunosuppressed transplant recipients: a meta-analysis. Lancet 370: 59-67.

10. Engels EA, Biggar RJ, Hall HI, Cross H, Crutchfield A, et al. (2008) Cancer risk in people infected with human immunodeficiency virus in the United States.Int J Cancer 123: 187-194.

11. Abraham AG, D'Souza G, Jing Y, Gange SJ, Sterling TR, et al. (2013) Invasive cervical cancer risk among HIV-infected women: a North American multicohort collaboration prospective study. J Acquir Immune DeficSyndr 62: 405-413.

12. International Agency for Research on Cancer (1996) IARC Monographs on the Evaluation of Carcinogenic Risks to Humans - Human Immunodeficiency Viruses 67.

13. International Agency for Research on Cancer (2012) A Review of Human Carcinogens: Biological Agents. IARC Monographs on the Evaluation of Carcinogenic Risks to Humans 100.

14. Dal Maso L, Polesel J, Serraino D, Lise M, Piselli P, et al. (2009) Pattern of cancer risk in persons with AIDS in Italy in the HAART era. Br J Cancer 100: 840-847.

15. Buchacz K, Baker RK, Palella FJ Jr, Chmiel JS, Lichtenstein KA, et al. (2010) AIDS-defining opportunistic illnesses in US patients, 1994-2007: a cohort study. AIDS 24: 1549-1559.

16. Adler DH (2010) The impact of HAART on HPV-related cervical disease. Curr HIV Res 8: 493-497.

17. Panel on Opportunistic Infections in HIV-Infected Adults and Adolescents (2013) Guidelines for the prevention and treatment of opportunistic infections in HIV-infected adults and adolescents: recommendations from the Centers for Disease Control and Prevention, the National Institutes of Health, and the HIV Medicine Association of the Infectious Diseases Society of America.

18. Lofters A, Glazier RH, Agha MM, Creatore MI, Moineddin R (2007) Inadequacy of cervical cancer screening among urban recent immigrants: a population-based study of physician and laboratory claims in Toronto, Canada. Prev Med 44: 536-542.

19. Lofters AK, Hwang SW, Moineddin R, Glazier RH (2010) Cervical cancer screening among urban immigrants by region of origin: a populationbased cohort study. Prev Med 51: 509-516.

20. Lofters AK, Moineddin R, Hwang SW, Glazier RH (2010) Low rates of cervical cancer screening among urban immigrants: a population-based study in Ontario, Canada. Med Care 48: 611-618.

21. Lofters AK, Moineddin R, Hwang SW, Glazier RH (2011) Predictors of low cervical cancer screening among immigrant women in Ontario, Canada. BMC Womens Health 11: 20.

22. Gupta A, Kumar A, Stewart DE (2002) Cervical cancer screening among South Asian women in Canada: the role of education and acculturation. Health Care Women Int 23: 123-134.

23. Akers AY, Newmann SJ, Smith JS (2007) Factors underlying disparities in cervical cancer incidence, screening, and treatment in the United States. CurrProbl Cancer 31: 157-181.

24. Arici C, Ripamonti D, Maggiolo F, Rizzi M, Finazzi MG, et al. (2002) Factors associated with the failure of HIV-positive persons to return for scheduled medical visits. HIV Clin Trials 3: 52-57.

25. Worthington C, McLeish K, Fuller-Thomson E (2012) Adherence over time to cervical cancer screening guidelines: insights from the Canadian National Population Health Survey. J Womens Health (Larchmt) 21: 199-208.

26. Kaplan JE, Parham DL, Soto-Torres L, van Dyck K, Greaves JA, et al. (1999) Adherence to guidelines for antiretroviral therapy and for preventing opportunistic infections in HIV-infected adults and adolescents in Ryan White-funded facilities in the United States. J Acquir Immune DeficSyndr 21: 228-235.

27. Stein MD, Cunningham WE, Nakazono T, Turner BJ, Andersen RM, et al. (2001) Screening for cervical cancer in HIV-infected women receiving care in the United States. J Acquir Immune DeficSyndr 27: 463-466. 
Citation: Andany N, Liu J, Remis R, Kaul R, Tharao WE, et al. (2014) Rates and Correlates of Self-Reported Pap Testing in African-CaribbeanBlack HIV-Positive Women in Ontario, Canada . J AIDS Clin Res 5: 364. doi:10.4172/2155-6113.1000364

Page 7 of 7

28. Oster AM, Sullivan PS, Blair JM (2009) Prevalence of cervical cancer screening of HIV-infected women in the United States. J Acquir Immune DeficSyndr 51: 430-436.

29. Dal Maso L, Franceschi S, Lise M, De' Bianchi PS, Polesel J, et al. (2010) Self-reported history of Pap-smear in HIV-positive women in Northern Italy: a cross-sectional study. BMC Cancer 10: 310.

30. Leece P, Kendall C, Touchie C, Pottie K, Angel JB, et al. (2010) Cervical cancer screening among HIV-positive women. Retrospective cohort study from a tertiary care HIV clinic. Can Fam Physician 56: e425-431.

31. Logan JL, Khambaty MQ, D'Souza KM, Menezes LJ (2010) Cervica cancer screening among HIV-infected women in a health department setting. AIDS Patient Care STDS 24: 471-475.

32. Rahangdale L, Sarnquist C, Yavari A, Blumenthal P, Israelski D (2010) Frequency of cervical cancer and breast cancer screening in HIV-infected women in a county-based HIV clinic in the Western United States. J Womens Health (Larchmt) 19: 709-712.

33. Setse R, Siberry GK, Moss WJ, Gravitt P, Wheeling T, et al. (2012) Cervical pap screening cytological abnormalities among HIV-infected adolescents in the LEGACY cohort. J PediatrAdolescGynecol 25: 27-34.

34. Bailey H, Thorne C, Semenenko I, Malyuta R, Tereschenko R, et al. (2012) Cervical screening within HIV care: findings from an HIVpositive cohort in Ukraine. PLoS One 7: e34706.

35. Keiser O, Martinez de Tejada B, Wunder D, Chapuis-Taillard C, Zellweger C, et al. (2006) Frequency of gynecologic follow-up and cervical cancer screening in the Swiss HIV cohort study. J Acquir Immune DeficSyndr 43: 550-555.

36. Baranoski AS, Horsburgh CR, Cupples LA, Aschengrau A, Stier EA (2011) Risk factors for nonadherence with Pap testing in HIV-infected women. J Womens Health (Larchmt) 20: 1635-1643.

37. Public Health Agency of Canada (2013) At a glance - HIV and AIDS in Canada: surveillance report to December 31, 2012.

38. Remis RS, Swantee C, Liu J (2012) Report on HIV/AIDS in Ontario 2009.

39. Public Health Agency of Canada (2012) Population-specific HIV/AIDS status report: women.

40. Remis RS, Liu J, Loutfy M, Tharao W, Rebbapragada A, et al. (2013) The epidemiology of sexually transmitted co-infections in HIV-positive and $\mathrm{HIV}$-negative African-Caribbean women in Toronto. BMC Infect Dis 13: 550.

41. Statistics Canada (2001) Canadian Community Health Survey (CCHS).

42. Dickinson JA, Stankiewicz A, Popadiuk C, Pogany L, Onysko J, et al. (2012) Reduced cervical cancer incidence and mortality in Canada: national data from 1932 to 2006. BMC Public Health 12: 992.
43. Sasieni PD, Cuzick J, Lynch-Farmery E (1996) Estimating the efficacy of screening by auditing smear histories of women with and without cervical cancer. The National Co-ordinating Network for Cervical Screening Working Group. Br J Cancer 73: 1001-1005.

44. Cancer Care Ontario. Ontario Cervical Screening Program Report 2003-2008.

45. Spayne J, Ackerman I, Milosevic M, Seidenfeld A, Covens A, et al. (2008) Invasive cervical cancer: a failure of screening. Eur J Public Health 18: 162-165.

46. Fehringer G, Howlett R, Cotterchio M, Klar N, Majpruz-Moat V, et al (2005) Comparison of papanicolaou (Pap) test rates across Ontario and factors associated with cervical screening. Can J Public Health 96: 140-144.

47. Elit L, Krzyzanowska M, Saskin R, Barbera L, Razzaq A, et al. (2012) Sociodemographic factors associated with cervical cancer screening and follow-up of abnormal results. Can Fam Physician 58: e22-31.

48. Elit L, Saskin R, Raut R, Elliott L, Murphy J, et al. (2013) Sociodemographic factors associated with cervical cancer screening coverage and follow-up of high grade abnormal results in a populationbased cohort study. Gynecol Oncol 128: 95-100.

49. Blackwell DL, Martinez ME, Gentleman JF (2008) Women's compliance with public health guidelines for mammograms and pap tests in Canada and the United States: an analysis of data from the Joint Canada/United States Survey Of Health. Womens Health Issues 18: 85-99.

50. Hewitt M, Devesa SS, Breen N (2004) Cervical cancer screening among U.S. women: analyses of the 2000 National Health Interview Survey. Prev Med 39: 270-278.

51. Bazargan M, Bazargan SH, Farooq M, Baker RS (2004) Correlates of cervical cancer screening among underserved Hispanic and AfricanAmerican women. Prev Med 39: 465-473.

52. Van Til L, MacQuarrie C, Herbert R (2003) Understanding the barriers to cervical cancer screening among older women. Qual Health Res 13: 1116-1131.

53. Serraino D, Pavia C, Navarra A, Piselli P, Pisani G, et al. (2005) Knowledge and use of papanicolaou test among HIV-positive women. Int J Cancer 115: 1009-1010.

54. Colgan TJ, Clarke A, Hakh N, Seidenfeld A (2002) Screening for cervical disease in mature women: strategies for improvement. Cancer 96: 195-203.

55. Chapman Lambert CL (2013) Factors influencing cervical cancer screening in women infected with HIV: a review of the literature. J Assoc Nurses AIDS Care 24: 189-197. 